\title{
Expression and diagnostic value of CCT3 and IQGAP3 in hepatocellular carcinoma
}

\author{
E-Na Qian, Shuang-Yin Han*, Song-Ze Ding and Xun Lv
}

\begin{abstract}
Background: To evaluate plasma chaperonin containing TCP1 complex subunit 3 (CCT3) and IQ-motif-containing GTPase-activating protein-3 (IQGAP3) as biomarker for hepatocellular carcinoma (HCC) screening and diagnosis.

Methods: Blood samples were collected from $126 \mathrm{HCC}$ patients with HCC, 88 patients with cirrhosis and 50 healthy volunteers to detect plasma a-fetoprotein (AFP), CCT3 and IQGAP3 levels. Plasma AFP, CCT3 and IQGAP3 protein levels were measured by enzyme linked immunosorbent assay (ELISA).

Results: In the plasma of HCC patients, both CCT3 and IQGAP3 were significantly higher than in patients with cirrhosis and in healthy controls $(P<0.01)$. CCT3 and IQGAP3 protein level correlated well with HCC etiology, tumor size, TNM stage, and child-pugh classification. CCT3 protein had higher sensitivity in the diagnosis of HCC when compared with AFP (87.3 vs $69.8 \%$ ). In addition, CCT3 and IQGAP3 protein were able to complement AFP in detecting AFP-negative HCC patients with sensitivity and specificity of 92.1 and $70.5 \%$ and 81.6 and $71.6 \%$, respectively. In the small HCC group, CCT3 and IQGAP3 protein had sensitivity of 76.6 and $74.5 \%$, respectively. The combination of AFP + CCT3 + IQGAP3 (0.954) had significantly superior discriminative ability than AFP alone $(0.815 ; P<0.01)$.
\end{abstract}

Conclusions: CCT3 and IQGAP3 are novel complementary biomarkers for HCC screening and diagnosis, especially for AFP-negative and small HCC patients.

Keywords: Hepatocellular carcinoma, Chaperonin containing TCP1 complex subunit 3, IQ-motif-containing GTPase-activating protein-3, a-Fetoprotein, Diagnostic biomarker

\section{Background}

Hepatocellular carcinoma (HCC) is the fifth most common cancer in the world and the third leading cause of cancer-related mortality, causing 696,000 deaths each year [1]. Although the prognosis of late-stage HCC has improved during the past two decades, its 5-year survival rate is still low [2].

The most effective therapy for $\mathrm{HCC}$ is surgical resection, but tumors at later stages may be inoperable. Traditional detection methods such as ultrasound, magnetic resonance imaging and computed tomography are helpful and efficient in detecting tumor location and metastasis, but cannot reliably detect early-stage HCC, and fail to diagnose $\mathrm{HCC}$ when they are used alone $[3,4]$. To date,

\footnotetext{
*Correspondence: 13903718702@163.com

Department of Gastroenterology and Hepatology, People's Hospital of Zhengzhou University, No. 7 Wei Wu Road, Zhengzhou 450003, Henan, China
}

$\alpha$-fetoprotein (AFP) is the most important serological marker recommended for screening patients at high-risk for HCC. However, nearly $40 \%$ of patients with HCC, including some with small tumors, have normal serological AFP levels [5]. Therefore, it is important to develop reliable biomarkers for early detection and diagnosis of $\mathrm{HCC}$ for clinical treatment and prognosis.

The chaperonin containing TCP1 complex (CCT), also called TRiC or c-cpn, mediates protein folding in the cytosol. Chaperonins are ATP-dependent protein-folding machines that are present in all kingdoms of life. They consist of two back-to-back stacked oligomeric rings with a cavity at each end, where protein substrate binding and folding take place $[6,7]$. The chaperonin family includes mitochondrial heat shock protein 60 , bacterial GroEL, plastid Rubisco subunit-binding protein, and archaea group II chaperonins $[8,9]$. CCT3 $(60 \mathrm{kDa})$ is a critical subunit in CCT/TRiC complexes, which plays a 
significant role in specifically binding these factors during protein folding or refolding. Several studies have shown by quantitative RT-PCR and western blotting that CCT3 is overexpressed in patients with HCC [10-14]. CCT3 can affect the progression of $\mathrm{HCC}$, by having an impact on the transport of phosphorylated signal transducer and activator of transcription (STAT)3/STAT3 into the nuclei of HCC cells. CCT3 may play a role in regulating microtubular structure and function (capture of kinetochores) and affect the cellular sensitivity to these microtubule-targeting agents. However, the role as a biomarker in HCC and other cancer has not been evaluated.

The IQ-motif-containing GTPase-activating protein (IQGAP) family comprises three members: IQGAP1, IQGAP2 and IQGAP3. IQGAP3 is the latest addition to this family. It was involved in the proliferation of epithelial cells, however, its role in tumorigenesis remains to be determined $[15,16]$. IQGAP3 promotes cell proliferation through the Ras/extracellular signal-regulated kinase (ERK) pathway [17]. Expression of IQGAP3 was increased during proliferation at sites of cell-cell contact in hepatocytes. Therefore, one of the most important future issues is to identify the cell-density-sensing units at cell-cell contacts in association with IQGAP3. The IQGAP3related signaling pathway may be one of the complex signaling routes involved in liver regeneration. The contribution of Ras-, Rac-, and Cdc42-binding IQGAP3 to liver regeneration suggests that IQGAP3 might lead to effective coordination of these signaling processes for cell proliferation and tissue remodeling [18].

Skawran et al. [13] found that CCT3 and IQGAP3 genes are all localized on 1q22 and they are up-regulated at the gene level in HCC. To date, it is not clear if CCT3 and IQGAP3 can be detected at the plasma level, nor is the relationship known between plasma AFP, CCT3 and IQGAP3 levels in different stages of HCC. In this study, we investigated CCT3 and IQGAP3 at plasma levels in patients with $\mathrm{HCC}$ or cirrhosis and in healthy individuals, and evaluated their application in detecting small and AFP-negative tumors in patients with HCC. Our results demonstrate that CCT3 and IQGAP3 are novel biomarkers complementary to AFP in HCC diagnosis, whose expression is probably independent of AFP. This is especially valuable when AFP is negative and $\mathrm{HCC}$ is at an early stage. Thus, determination of CCT3 and IQGAP3 in combination with AFP increases the diagnostic sensitivity and specificity of HCC.

\section{Methods}

\section{Patient information}

We enrolled 126 HCC patients, 88 patients with cirrhosis, and 50 healthy individuals from People's Hospital of Zhengzhou University (Henan, China) between May
2014 and September 2015. Patients were evaluated and diagnosed by physical examination, laboratory tests, ultrasonography, computed tomography or magnetic resonance imaging. In patients who underwent surgery, HCC was confirmed by pathological examination. No patients received preoperative radiotherapy or chemotherapy and none of the cancer patients had other types of malignancy. HCC was staged according to the childpugh and tumor-node-metastasis (TNM) classifications [19]. Details about the patients with HCC or cirrhosis are listed in Tables 1 and 2. The Hospital Ethics Committee approved this study. All participants were fully informed and gave written informed consent.

\section{Blood sampling}

Peripheral blood samples $(3-5 \mathrm{~mL})$ from each patient were collected in anti-coagulated tubes containing ethylene diamine tetraacetie acid (EDTA). All blood samples from patients with HCC were collected before surgery. The samples from healthy donors were obtained from the Hospital Physical Examination Center. Samples were centrifuged at $1000 \times g$ for $15 \mathrm{~min}$ at room temperature, and stored at $-80{ }^{\circ} \mathrm{C}$ until testing.

\section{Measurement of plasma AFP, CCT3 and IQGAP3 protein levels}

Plasma CCT3 and IQGAP3 (sensitivity, $5.0 \mathrm{pg} / \mathrm{mL}$; assay range $31.2-1000 \mathrm{pg} / \mathrm{mL}$ ) levels were measured using a commercially available ELISA kit (Novatein Biosciences, Woburn, MA, USA). Plasma AFP levels were detected using an ELISA kit (R\&D Systems, Minneapolis, MN, USA) (sensitivity, $0.046 \mathrm{ng} / \mathrm{mL}$; assay range $0.312-$ $20.0 \mathrm{ng} / \mathrm{mL}$ ). Ten microliters of plasma samples were mixed with $40 \mu \mathrm{L}$ of sample dilution buffer and incubated in 96-well plates coated with antibodies for $30 \mathrm{~min}$ at $37^{\circ} \mathrm{C}$. The solutions were decanted followed by washing. Fifty-microliter horseradish-peroxidase-conjugated secondary antibodies were added to the wells and incubated for $30 \mathrm{~min}$. After washing, $50 \mu \mathrm{L}$ of each chromogen solution A and chromogen solution B were added to the wells, and incubated for $15 \mathrm{~min}$ at $37^{\circ} \mathrm{C}$. The reaction was stopped by adding $50 \mu \mathrm{L}$ stop solution. The OD values were determined in a 96-well plate reader (Bio-Rad Laboratories, Hercules, MA, USA) at $450 \mathrm{~nm}$. All tests were performed in duplicate. Average OD values were calculated and the plasma levels of CCT3, IQGAP3 and AFP proteins were determined by standard curve. Data were collected and analyzed, intra-batch variation was controlled within $5 \%$, and inter-batch variation was $<10 \%$.

\section{Statistical analysis}

All data are summarized and expressed as the mean \pm SD. The Mann-Whitney $U$ test or Kruskal-Wallis test was 
Table 1 Clinical characteristics of patients with HCC

\begin{tabular}{|c|c|c|c|c|c|}
\hline \multirow[t]{2}{*}{ Parameters } & \multirow[t]{2}{*}{ Patients, n (\%) } & ССТ3 & \multirow[t]{2}{*}{$P$ value } & IQGAP3 & \multirow[t]{2}{*}{$P$ value } \\
\hline & & $\bar{x} \pm S D, p g / m L$ & & $\bar{x} \pm S D, p g / m L$ & \\
\hline \multicolumn{6}{|l|}{ Age (years) } \\
\hline$\leq 55$ & $38(30.2)$ & $285.53 \pm 203.38$ & \multirow[t]{2}{*}{$0.106^{\mathrm{a}}$} & $217.79 \pm 163.06$ & \multirow[t]{2}{*}{$0.043^{\mathrm{a}}$} \\
\hline$>55$ & $88(69.8)$ & $350.6 \pm 207.33$ & & $287.83 \pm 181.55$ & \\
\hline \multicolumn{6}{|l|}{ Gender } \\
\hline Male & $84(66.7)$ & $354.67 \pm 217.39$ & \multirow[t]{2}{*}{$0.08^{\mathrm{a}}$} & $270.35 \pm 167.19$ & \multirow[t]{2}{*}{$0.748^{\mathrm{a}}$} \\
\hline Female & $42(33.3)$ & $283.6 \pm 199.51$ & & $259.43 \pm 201.11$ & \\
\hline \multicolumn{6}{|l|}{ Etiology } \\
\hline $\mathrm{HBV}(+)$ & $72(57.1)$ & $284.79 \pm 195.82$ & \multirow[t]{3}{*}{$0.019^{b}$} & $218.82 \pm 177.52$ & \multirow[t]{3}{*}{$0.002^{b}$} \\
\hline $\mathrm{HCV}(+)$ & $31(24.6)$ & $407.16 \pm 209.483$ & & $342.32 \pm 150.01$ & \\
\hline Other & $23(18.3)$ & $72.87 \pm 209.96$ & & $314.70 \pm 74.99$ & \\
\hline \multicolumn{6}{|c|}{ Tumor diameter $(\mathrm{cm})$} \\
\hline$\leq 2$ & $47(37.3)$ & $279.13 \pm 217.01$ & \multirow[t]{3}{*}{$0.011^{b}$} & $212.74 \pm 170.72$ & \multirow[t]{3}{*}{$0.025^{b}$} \\
\hline$>2$ and $\leq 5$ & $25(19.8)$ & $432.92 \pm 155.60$ & & $327.80 \pm 138.07$ & \\
\hline$>5$ & $54(42.9)$ & $328.91 \pm 205.99$ & & $285.39 \pm 191.04$ & \\
\hline \multicolumn{6}{|c|}{ Number of lesions } \\
\hline$\leq 2$ & $61(48.4)$ & $272.52 \pm 200.87$ & \multirow[t]{2}{*}{$0.002^{\mathrm{a}}$} & $230.36 \pm 166.22$ & \multirow[t]{2}{*}{$0.026^{\mathrm{a}}$} \\
\hline$>2$ & $65(51.6)$ & $385.83 \pm 199.91$ & & $300.82 \pm 184.04$ & \\
\hline \multicolumn{6}{|c|}{ Extra-hepatic metastasis } \\
\hline Yes & $34(27.0)$ & $407.00 \pm 215.60$ & \multirow[t]{2}{*}{$0.014^{\mathrm{a}}$} & $334.03 \pm 207.84$ & \multirow[t]{2}{*}{$0.27^{\mathrm{a}}$} \\
\hline No & $92(73.0)$ & $302.88 \pm 198.33$ & & $241.83 \pm 160.53$ & \\
\hline \multicolumn{6}{|c|}{ Differentiation degree } \\
\hline Well & $47(37.3)$ & $316.21 \pm 208.54$ & \multirow[t]{3}{*}{$0.245^{b}$} & $252.85 \pm 154.02$ & \multirow[t]{3}{*}{$0.133^{b}$} \\
\hline Moderate & $43(34.1)$ & $308.37 \pm 201.41$ & & $235.53 \pm 178.15$ & \\
\hline Poor & $36(28.6)$ & $377.25 \pm 211.73$ & & $322.03 \pm 199.74$ & \\
\hline \multicolumn{6}{|l|}{ TNM stage } \\
\hline $1+\|$ & $71(56.3)$ & $282.56 \pm 199.01$ & \multirow[t]{2}{*}{$0.003^{\mathrm{a}}$} & $232.5 \pm 158.43$ & \multirow[t]{2}{*}{$0.017^{a}$} \\
\hline$I I I+I V$ & $55(43.7)$ & $393.47 \pm 203.17$ & & $310.85 \pm 194.09$ & \\
\hline Child-pugh c & & & & & \\
\hline A & $51(40.4)$ & $265.75 \pm 209.34$ & $0.006^{b}$ & $203.08 \pm 164.94$ & $0.000^{b}$ \\
\hline B & $33(26.3)$ & $400.58 \pm 199.30$ & & $357.45 \pm 149.83$ & \\
\hline C & $42(33.3)$ & $355.50 \pm 192.4$ & & $272.67 \pm 186.31$ & \\
\hline
\end{tabular}

HBV hepatics B virus, HCV hepatics C virus, HCC hepatocellular carcinoma, SD standard deviation, TNM tumor-node-metastasis

a By Mann-Whitney $U$ test

${ }^{b}$ By Kruskal-Wallis test

Table 2 CCT3 and IQGAP3 protein level in different patient groups

\begin{tabular}{lcclcc}
\hline Groups & Patients $(\boldsymbol{n})$ & CCT3 mean \pm SD, $\mathbf{p g} / \mathbf{m L}$ & $\boldsymbol{P}$ value & IQGAP3 mean \pm SD, pg/mL & $P$ value \\
\hline Total HCC & 126 & $330.98 \pm 207.51$ & $<0.01^{*}$ & $266.71 \pm 178.47$ & $<0.01^{*}$ \\
Cirrhosis & 88 & $82.03 \pm 96.53$ & $<0.05^{* *}$ & $66.44 \pm 63.97$ & $>0.05^{*}$ \\
Healthy controls & 50 & $50.34 \pm 27.27$ & $<0.01^{* * *}$ & $59.50 \pm 51.08$ & $<0.01^{* * *}$ \\
AFP-negative HCC & 38 & $337.66 \pm 202.55$ & $<0.01^{*}$ & $261.05 \pm 171.20$ & $<0.01^{*}$ \\
Small HCC & 47 & $279.13 \pm 217.02$ & $<0.01^{*}$ & $212.74 \pm 170.73$ & $<0.01^{*}$ \\
AFP-negative small HCC & 27 & $306.56 \pm 1196.48$ & $<0.01^{*}$ & $232.41 \pm 149.13$ & $<0.01^{*}$ \\
\hline
\end{tabular}

\footnotetext{
* $P<0.05$ (vs. cirrhosis)

** $P<0.05$ (vs. healthy controls

*** $P<0.05$ (vs. HCC)

\# $P>0.05$ (vs. healthy controls)
} 
used to compare the distribution of CCT3 and IQGAP3 levels and clinical variables among HCC groups. All $P$ values were derived from two-sided tests, and $P<0.05$ was considered statistically significant. Correlation between CCT3 and IQGAP3 levels was assessed using Spearman correlation test. To compare abilities of tumor markers in diagnosis of HCC, receiver operator characteristic (ROC) curves, which correlate true- and false-positive rates [sensitivity and $(1-$ specificity)], were constructed using the RocKIT (University of Chicago,USA). A logistic regression model was used to analyze sensitivity and specificity of biomarkers. Additionally, areas under the ROC curve (AUC) were calculated for each marker. The statistical significance of differences between the two AUCs was determined. The optimal cutoff values were calculated using the maximum sum of sensitivity and specificity. Statistical analysis was conducted using SPSS for Windows version 17.0 (SPSS Inc., Chicago, IL, USA).

\section{Results}

\section{Clinicopathological features of serum CCT3 and IQGAP3} expression in HCC patients

Clinical characteristics of all $126 \mathrm{HCC}$ patients (84 male and 42 female) were shown in Table 1: $57.1 \%$ had HBV-related hepatitis; $24.6 \%$ had HCV-related hepatitis; $37.3 \%$ had small tumors (single nodule and diameter $\leq 2 \mathrm{~cm}$ ); and $30.1 \%$ had AFP-negative HCC $(<20.0 \mathrm{ng} / \mathrm{mL})$. The patients in HCC group, $56.3 \%$ were staged as TNM I + II and $43.7 \%$ as III + IV; $40.4 \%$ of patients were classified as child-pugh A, $26.3 \%$ as childpugh $B$ and $33.3 \%$ as child-pugh $C$. We found that CCT3 and IQGAP3 protein levels were correlated with etiology of HCC, tumor size, number of cancer nodules and child-pugh classification $(P<0.05)$. Furthermore, (Fig. 1) also indicated that there was correlation between plasma CCT3 and IQGAP3 levels $(r=0.824$, $P<0.01$ ).

\section{Serum CCT3 and IQGAP3 level in patients with liver diseases and healthy controls}

To investigate concentration of serum CCT3 and IQGAP3 in patients with different liver diseases and healthy persons, the levels of CCT3 and IQGAP3 in peripheral blood were detected by ELISA. Expression of serum CCT3 in patients with HCC (330.98 $\pm 207.51 \mathrm{pg} /$ $\mathrm{mL})$ was significantly higher $(P<0.001)$ than in patients with cirrhosis $(82.03 \pm 96.53 \mathrm{pg} / \mathrm{mL})$, or healthy controls $(50.34 \pm 27.27 \mathrm{pg} / \mathrm{mL})$ (Table 2). Similarly, expression of serum IQGAP3 in patients with HCC $(266.71 \pm 178.47 \mathrm{pg} / \mathrm{mL})$ was evidently higher $(P<0.001)$ than that in patients with cirrhosis $(66.44 \pm 63.97 \mathrm{pg} /$ $\mathrm{mL})$, or healthy controls $(59.50 \pm 51.08 \mathrm{pg} / \mathrm{mL})$.

\section{Plasma CCT3 and IQGAP3 protein levels in patients} with small and AFP-negative tumors

We compared the levels of CCT3 and IQGAP3 protein in patients with small $(n=47)$ and AFP-negative $(n=38)$ tumors. In the small HCC group, the CCT3 AUC was 0.761, with $95 \%$ Confidence interval (CI) 0.663-0.860, and IQGAP3 AUC was 0.753 (95\% CI 0.651-0.855). AFP AUC was 0.707 (95 \% CI 0.604-0.811). CCT3 and IQGAP3 had a larger AUC than AFP had (Fig. 2a, $P<0.01)$. When the cut-off value for CCT3 was selected at $46.5 \mathrm{pg} / \mathrm{mL}$, as determined by maximum sensitivity and specificity, the sensitivity and specificity for CCT3 were 76.6 and $70.5 \%$, respectively. When the cut-off value for IQGAP3 was selected at $43.5 \mathrm{pg} / \mathrm{mL}$, the sensitivity and specificity for IQGAP3 were 74.5 and $71.6 \%$, respectively, while the sensitivity and specificity for AFP (20 ng/mL), were 53.2 and $68.2 \%$, respectively. Thus, CCT3 and IQGAP3 showed superiority to AFP in detecting small $\mathrm{HCC}$ tumors.

In addition, plasma CCT3 and IQGAP3 from 38 AFPnegative $\mathrm{HCC}$ and 88 cirrhosis patients were analyzed. Their AFP levels were $<20 \mathrm{ng} / \mathrm{mL}$. AUC for CCT3 was 0.871 (95 \% CI 0.791-0.951, Fig. 2b, $P<0.01$ ). When the cut-off value for CCT3 was selected at $46.5 \mathrm{pg} / \mathrm{mL}$, the sensitivity was $92.1 \%$ and specificity was $70.5 \%$. AUC for IQGAP3 was 0.804 (95 \% CI 0.694-0.914, Fig. 2b, $P<0.01$ ). When the cut-off value for IQGAP3 was selected at $43.5 \mathrm{pg} / \mathrm{mL}$, the sensitivity was $81.6 \%$ and specificity was $71.6 \%$.

Furthermore, among 47 patients with small HCC, 27 were negative for AFP. Their AUC for CCT3 was 0.84 (95\% CI 0.735-0.945, Fig. 2c, $P<0.01$ ) when differentiating from cirrhosis; its sensitivity and specificity were 88.9 and $70.5 \%$, respectively, when the cut-off value was selected at $46.5 \mathrm{pg} / \mathrm{mL}$. AUC for IQGAP3 was 0.822 (95\% CI 0.700-0.943, Fig. 2c, $P<0.01$ ); when differentiating from cirrhosis, its sensitivity and specificity were 85.2 and $71.6 \%$, respectively, when the cut-off value was selected at $43.5 \mathrm{pg} / \mathrm{mL}$.

\section{Combined diagnostic value of plasma CCT3, IQGAP3 and AFP}

AUC was calculated to compare the accuracy achieved when using AFP, CCT3 and IQGAP3 for diagnosis of HCC (Fig. 2d). AUC for AFP $(0.815,95 \%$ CI $0.758-$ $0.872)$ and CCT3 $(0.846,95 \%$ CI $0.791-0.901)$ was higher than for IQGAP3 $(0.808,95 \%$ CI $0.747-0.869)$. High levels of plasma CCT3 protein were detected in HCC, and CCT3 had higher sensitivity (87.3\%) than AFP (69.8 \%) in differentiating HCC from cirrhosis when the cut-off value was selected at $46.5 \mathrm{pg} / \mathrm{mL}$ and $20 \mathrm{ng} / \mathrm{mL}$, respectively $(P<0.05)$. We also analyzed the 


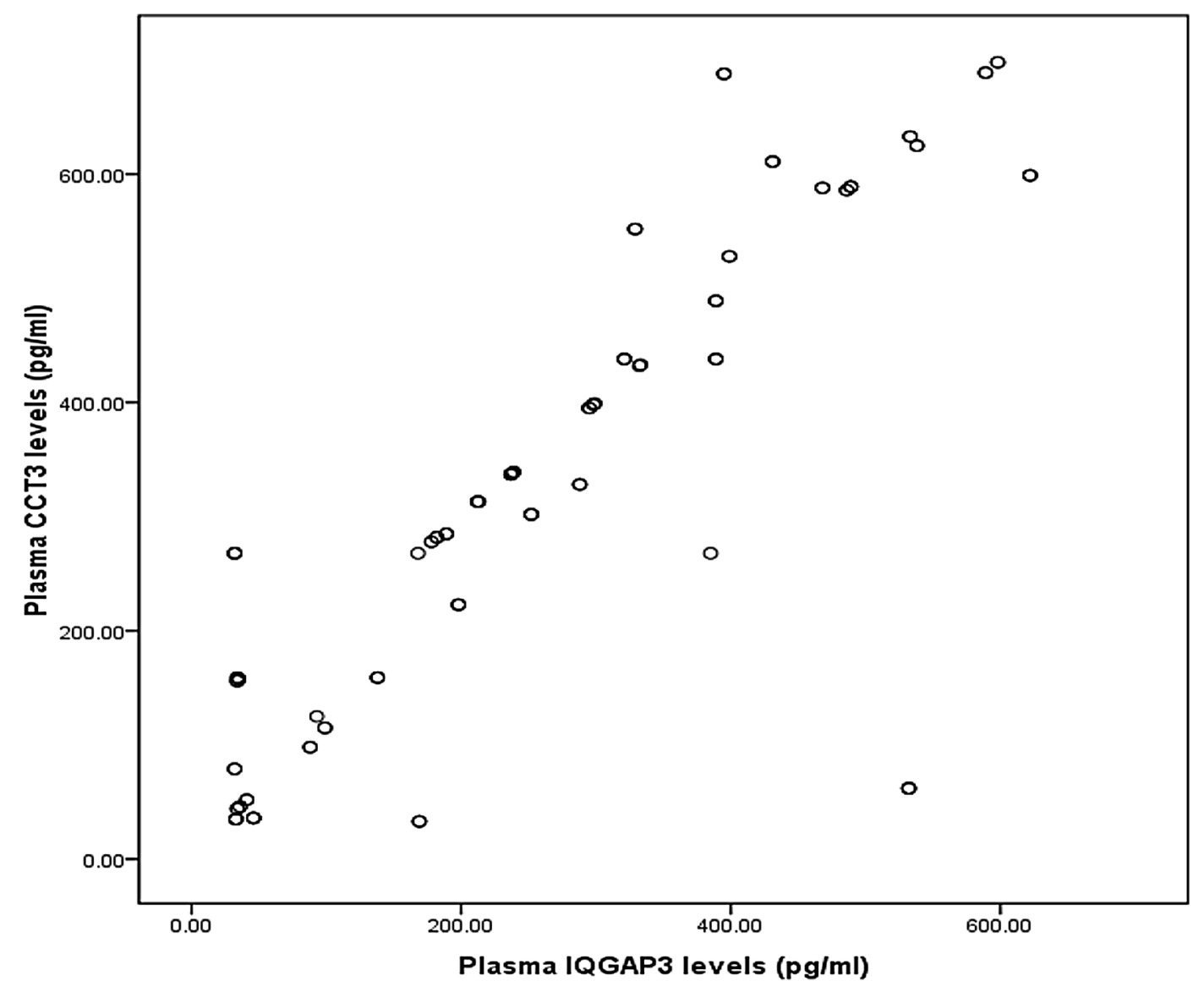

Fig. 1 Correlation plasma CCT3 levels with IQGAP3 levels. The correlation of CCT3 level with IQGAP3 level was analyzed in 126 HCC patients. Points show CCT3 or IQGAP3 levels of each of participants, with X axle indicates IQGAP3 levels (pg/mL), and Y axle indicates CCT3 levels ( $\mathrm{pg} / \mathrm{mL}$ )

complementary properties of using CCT3 and IQGAP3 in combination with AFP for the diagnosis of HCC, using a logistic regression model,with " 0 " represents the cirrhosis group, " 1 " represents liver cancer. Obtain the following regression equation: $\mathrm{P}=1 /\left[1+\mathrm{e}^{-(-3.413+0.007 \mathrm{X} 1+}\right.$ $0.020 \mathrm{X} 2+0.007 \mathrm{X} 3)], \mathrm{X} 1, \mathrm{X} 2$ and $\mathrm{X} 3$ respectively represents AFP, CCT3 and IQGAP3, values of OR were: $1.008,1.020$ and 1.007 , respectively. $95 \%$ Confidence intervals were (1.007-1.012), (1.010-1.031), (1.001-1.012), respectively (Table 3). Thus, CCT3, IQGAP3 and AFP are the independent factors of HCC. High risk of HCC in patients with high expression of CCT3 is 1.200 times that of lower levels, AFP is 1.008 times and IQGAP3 is 1.007 times, respectively. Thus, the expression of CCT3 and IQGAP3 are independent of AFP.

The combined use of AFP, CCT3 and IQGAP3 further increased the AUC (0.954; $95 \%$ CI 0.925-0.982), which was higher than that just using AFP alone (Fig. 2e $P<0.01$ ).

\section{Discussion}

HCC is one of the most severe types of cancer. It has a high incidence and is the third most common cause of cancer mortality, with 696,000 cases worldwide each year [20-22]. The mortality is partly due to unresponsiveness to treatment, and the 5-year survival rate was $<5 \%$ after diagnosis [23]. AFP is a commonly used tumor marker for the early screening of primary HCC. However, AFP as a sole indicator of HCC is of limited value. Statistical data confirmed that the diagnostic sensitivity of AFP for small HCC tumors is only $20-40 \%$. Nearly one-third of early stage, small HCC tumors $(<2 \mathrm{~cm})$ cannot be detected using AFP screening [24, 25]. In contrast, the level of serum AFP does not reflect the severity of the patient's condition, nor effectively assess HCC prognosis.

Eukaryotic CCT3 consists of two identical rings, each with eight different CCT subunits. Through a variety of structural, functional and cell biology methods, interactions between TRiC and its main substrates, actin and 

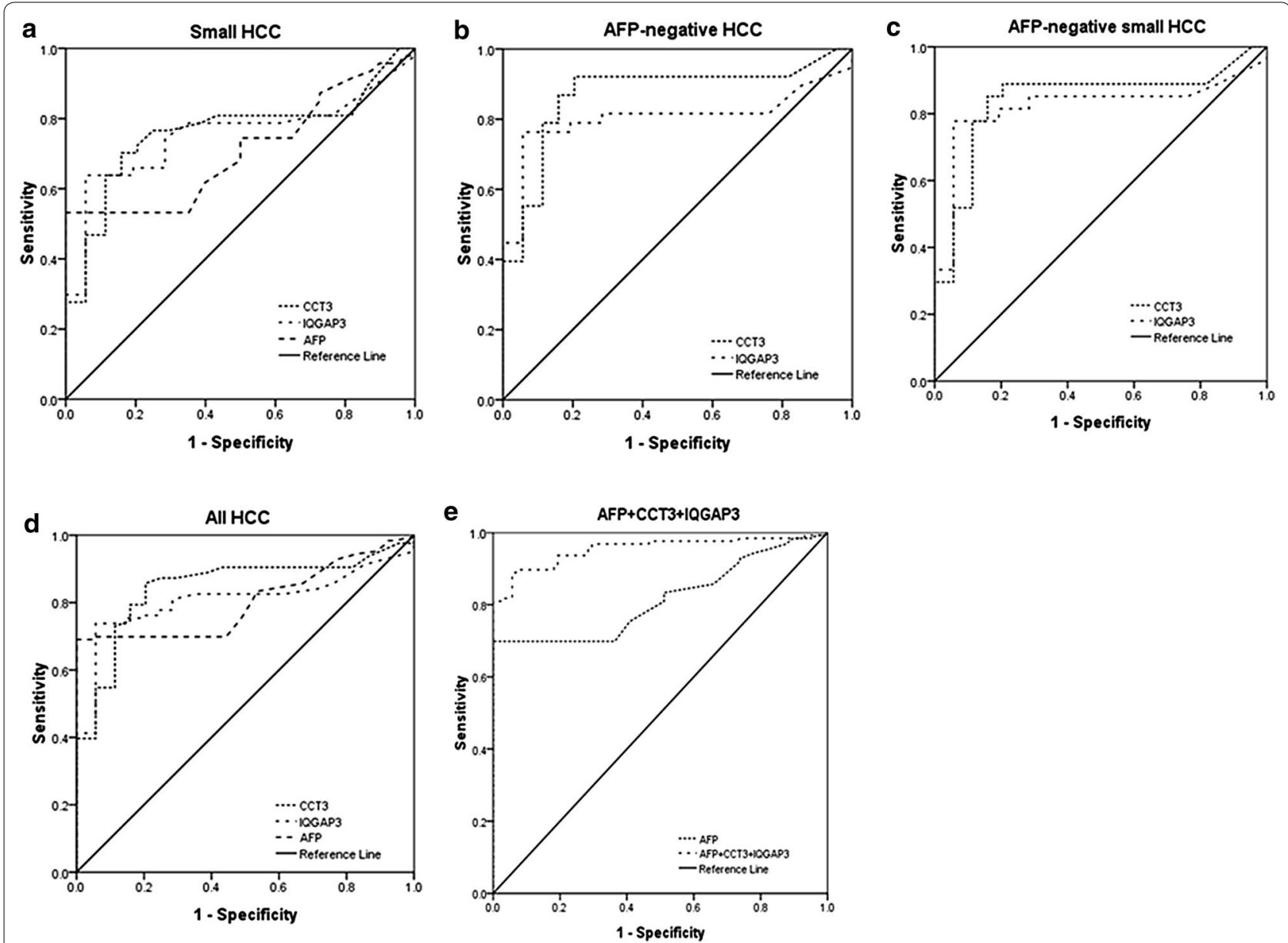

Fig. 2 ROC curve of CCT3,IQGAP3 and AFP in HCC, cirrhosis patients. ROC curve were used to analyze the diagnostic performance of CCT3 and IQGAP3 from different groups. The area under the ROC curve (AUC) was shown with $95 \%$ Confidence intervals. a ROC curve of CCT3 and IQGAP3 in differentiating small HCC from cirrhosis patients. b ROC curve of CCT3 and IQGAP3 in differentiating AFP-negative HCC from cirrhosis patients. $\mathbf{c}$ ROC curve of CCT3 and IQGAP3 in differentiating AFP-negative small HCC from cirrhosis patients. $\mathbf{d}$ ROC curve of comparing the accuracy achieved when using AFP, CCT3 and IQGAP3 for diagnosis of HCC. e ROC curve of AFP and combined use of AFP, CCT3 and IQGAP3

Table 3 Logistic regression analysis

\begin{tabular}{lclll}
\hline Factor & Regression coefficient & $\boldsymbol{P}$ & OR & $\mathbf{9 5} \% \mathbf{C l}$ \\
\hline AFP & 0.007 & 0.001 & 1.008 & $1.007-1.012$ \\
CCT3 & 0.020 & 0.000 & 1.020 & $1.010-1.031$ \\
IQGAP3 & 0.007 & 0.000 & 1.007 & $1.001-1.012$ \\
Constant & -3.413 & 0.000 & 0.033 & \\
\hline
\end{tabular}

tubulin, have been well characterized [26, 27]. The chaperonins are key molecular complexes that are essential in protein folding to produce stable and functionally competent protein conformations [28, 29]. In this study, high levels of plasma CCT3 protein were detected in HCC, and CCT3 had better sensitivity (87.3\%) than AFP (69.8\%) in differentiating HCC from cirrhosis. Furthermore, the AUC for CCT3 (0.865) was larger than that of
AFP (0.815), which is consistent with Yokota et al. [30] who reported increased expression of cytosolic chaperonin CCT in human HCC and colonic carcinoma. Significant overexpression of CCT3 in HCC has also been reported by Wong et al. [12].

IQGAPs is a newly discovered protein family and its sequence displays extensive sequence similar to the catalytic domain of RasGAPS, and four IQ motifs located in the $\mathrm{N}$-terminal which can interact with calmodulin, and in mammals there are three homologous IQGAPs 1-3. IQGAP3 is located at 1q22, which is a hotspot for gene amplification in cancer and expressed in liver and intestines and other organs restrictively [31]. DNA amplification at $1 \mathrm{q} 22$ is linked with gastroesophageal carcinoma and infiltrating ductal carcinoma of the breast [32, 33]. In this study, we observed higher levels of serum IQGAP3 in patients with HCC than in patients without 
HCC. Skawran et al. [13] demonstrated that CCT3 and IQGAP3 are upregulated most significantly by gene set enrichment analysis in HCC.

In this work, we found that concentration of serum CCT3 and IQGAP3 in patients with HCC was correlated with etiology, tumor size, number of cancer nodules and child-pugh classification, indicating that they are novel predictors for HCC. Yuan et al. reported that CCT3 has the potential as a new tumor marker for early detection of cholangiocarcinoma [34]. Ying et al. demonstrated that IQGAP3 may contribute to the pathogenesis of lung cancer by modulating GFR-ERK signaling [35].

The prognosis of HCC can be largely improved if it is detected at an early stage. However, detection of early stage and AFP-negative HCC is still difficult clinically, even with the help of advanced imaging technology. Accurate detection of AFP-negative and small $\mathrm{HCC}$ tumors can lead to early diagnosis, treatment, and reduced cancer-related mortality. This study showed that CCT3 and IQGAP3 are superior to AFP in predicting HCC prognosis. In AFP-negative HCC group, the sensitivity of CCT3 and IQGAP3 was 92.1 and $81.6 \%$ and specificity was $70.5,71.6 \%$, respectively. We also evaluated whether CCT3 and IQGAP3 could be used as markers for the detection of small HCC tumors. Our data showed that serum CCT3 levels in patients with small tumors $(\leq 2 \mathrm{~cm})$ provided a sensitivity of $76.6 \%$ when distinguishing small HCC from cirrhosis at a cut-off value of $46.5 \mathrm{pg} / \mathrm{mL}$. IQGAP3 had sensitivity of $74.5 \%$ when distinguishing small HCC from cirrhosis at a cutoff value of $43.5 \mathrm{pg} / \mathrm{mL}$. AFP had a sensitivity of $74.5 \%$. In the AFP-negative small HCC group, the sensitivity of CCT3 and IQGAP3 was 88.9 and $85.2 \%$, respectively. These results suggest that CCT3 and IQGAP3 can be complementary to AFP in the diagnosis of AFP-negative and small HCC.

Combination of CCT3, IQGAP3 and AFP could significantly increase the sensitivity of each agent for HCC diagnosis. However, the specificity is also reduced. The combined use of AFP, CCT3 and IQGAP3 further increased the AUC (0.954; $95 \%$ CI 0.925-0.982), which was higher than that using AFP alone $(0.815 ; 95 \% \mathrm{CI}$ 0.758-0.872).

\section{Conclusions}

In summary, our findings indicate that CCT3 and IQGAP3 are novel biomarkers complementary to AFP in HCC diagnosis, whose expression is independent of AFP. This is especially valuable when AFP is negative and HCC is at an early stage. Thus, CCT3 and IQGAP3 should be useful biomarkers, in combination with AFP, to confirm the diagnosis of HCC. Future works are required to explore whether CCT3 and IQGAP3 can also predict patients' survival and their usefulness in clinical application.

\section{Abbreviations}

CCT3: chaperonin containing TCP1 complex subunit 3; IQGAP3: IQ-motifcontaining GTPase-activating protein-3; HCC: hepatocellular carcinoma; ELISA: enzyme linked immunosorbent assay; AFP: a-fetoprotein; ERK: Ras/extracellular signal-regulated kinase; TNM: tumor-node-metastasis; EDTA: ethylene diamine tetraacetie acid; AUC: areas under the ROC curve.

\section{Authors' contributions}

Conception and design: HSY, DSZ. Collection and assembly of data: QEN, LX. Data analysis and interpretation: DSZ, QEN. Contribution of reagents, materials, and analysis tools: HSY, DSZ, QEN, LX, QEN wrote the paper. All authors read and approved the final manuscript.

\section{Acknowledgements}

This work was supported by the National Natural Science Fundation of China as a framework of the program "Experimental study of tumor targeting therapy with iCaspase 9 control of chimeric $T$ cell receptor induced by suicide gene" (No. 81372405).

\section{Competing interests}

The authors declare that they have no competing interests.

Received: 24 May 2016 Accepted: 23 June 2016

Published online: 07 July 2016

\section{References}

1. Dhanasekaran R, Limaye A, Cabrera R. Hepatocellular carcinoma: current trends in worldwide epidemiology, risk factors, diagnosis and therapeutics. Hepat Med. 2012;4:19-37.

2. Farazi PA, DePinho RA. Hepatocellular carcinoma pathogenesis: from genes to environment. Nat Rev Cancer. 2006;6:674-87.

3. Takayasu K, Muramatsu Y, Mizuguchi Y, Moriyama N, Ojima H. Imaging of early hepatocellular carcinoma and adenomatous hyperplasia (dysplastic nodules) with dynamic CT and a combination of CT and angiography: experience with resected liver specimens. Intervirology. 2004;47:199-208.

4. Frericks BB, Loddenkemper C, Huppertz A, Valdeig S, Stroux A, Seja M, Wolf KJ, Albrecht T. Qualitative and quantitative evaluation of hepatocellular carcinoma and cirrhotic liver enhancement using Gd-EOB-DTPA. Am J Roentgenol. 2009;193:1053-60.

5. Attwa MH, El-Etreby SA. Guide for diagnosis and treatment of hepatocellular carcinoma. World J Hepatol. 2015:7:1632-51.

6. Kabir MA, Uddin W, Narayanan A, Reddy PK, Jairipuri MA, Sherman F, Ahmad Z. Functional subunits of eukaryotic chaperonin CCT/TRiC in protein folding. J Amino Acids. 2011;2011:843206.

7. Joachimiak LA, Walzthoeni T, Liu C, Aebersold R, Frydman J. The structural basis of substrate recognition by the eukaryotic chaperonin TRiC/CCT. Cell. 2014;159:1042-55.

8. Veenstra TD, Conrads TP, Hood BL, Avellino AM, Ellenboqen RG, Morrison RS. Biomarkers: mining the biofluid proteome. Mol Cell Proteom. 2005:4:409-18

9. Tracy CM, Gray AJ, Cuéllar J, Shaw TS, Howlett AC, Taylor RM, Prince JT, Ahn NG, Valpuesta JM, Willardson BM. Programmed cell death protein 5 Interacts with the cytosolic chaperonin containing tailless complex polypeptide 1 (CCT) to regulate $\beta$-tubulin folding. J Biol Chem. 2014;289:4490-502.

10. Cui X, Hu ZP, Li Z, Gao PJ, Zhu JY. Overexpression of chaperonin containing TCP1, subunit 3 predicts poor prognosis in hepatocellular carcinoma. World J Gastroenterol. 2015;21:8588-604.

11. Zhang Y, Wang Y, Wei Y, Wu J, Zhang P, Shen S, Saiyin H, Wumaier R, Yang X, Wang C, Yu L. Molecular chaperone CCT3 supports proper mitotic progression and cell proliferation in hepatocellular carcinoma cells. Cancer Lett. 2016;372:101-9. 
12. Wong $N$, Chan A, Lee SW, Lam E, To KF, Lai PB, Li XN, Liew CT, Johnson PJ. Positional mapping for amplified DNA sequences on 1q21-q22 in hepatocellular carcinoma indicates candidate genes over-expression. J Hepatol. 2003;38:298-306.

13. Skawran B, Steinemann D, Weigmann A, Flemming P, Becker T, Flik J, Kreipe H, Schlegelberger B, Wilkens L. Gene expression profiling in hepatocellular carcinoma: upregulation of genes in amplified chromosome regions. Mod Pathol. 2008;21:505-16.

14. Peters DG, Kudla DM, Deloia JA, Chu TJ, Fairfull L, Edwards RP, Ferrell RE. Comparative gene expression analysis of ovarian carcinoma and normal ovarian epithelium by serial analysis of gene expression. Cancer Epidemiol Biomarkers Prev. 2005;14:1717-23.

15. Atcheson E, Hamilton E, Pathmanathan S, Greer B, Harriott P, Timson DJ. IQ-motif selectivity in human IQGAP2 and IQGAP3: binding of calmodulin and myosin essential light chain. Biosci Rep. 2011;31(Pt5):371-9.

16. Schmidt VA. Watch the GAP:emerging roles for IQ motif-containing GTPase-activating proteins IQGAPs in hepatocellular carcinoma. Int J Hepatol. 2012;2012:958673.

17. Nojima H, Adachi M, Matsui T, Okawa K, Tsukita S, Tsukita S. IQGAP3 regulates cell proliferation through the Ras/ERK signalling cascade. Nat cell boil. 2008;10:971-8.

18. Kunimoto K, Nojima H, Yamazaki Y, Yoshikawa T, Okanoue T, Tsukita S. Involvement of IQGAP3, a regulator of Ras/ERK-related cascade, in hepatocyte proliferation in mouse liver regeneration and development. J Cell Physiol. 2009;220:621-31.

19. Edqe SB, Compton CC. The American Joint Committee on Cancer: the 7th edition of the AJCC cancer staging manual and the future of TNM. Ann Surg Oncol. 2010;17:1471-4.

20. Shariff MI, Cox IJ, Gomaa Al, Khan SA, Gedroyc W, Taylor-Robinson SD. Hepatocellular carcinoma: current trends in worldwide epidemiology, risk factors, diagnosis, and therapeutics. Expert Rev Gastroenterol Hepatol. 2009;3:353-67.

21. Tu T, Budzinska MA, Maczurek AE, Cheng R, Di Bartolomeo A, Warner FJ, McCaughan GW, McLennan SV, Shackel NA. Novel aspects of the liver microenvironment in hepatocellular carcinoma pathogenesis and development. Int J Mol Sci. 2014;15:9422-58.

22. Zheng T, Chen M, Han S, Zhang L, Bai Y, Fang X, Ding SZ, Yang Y. Plasma minichromosome maintenance complex component 6 is a novel biomarker for hepatocellular carcinoma patients. Hepatol Res. 2014:44:1347-56.

23. Yim HJ, Suh SJ, Um SH. Current management of hepatocellular carcinoma: an Eastern perspective. World J Gastroenterol. 2015;21:3826-42.
24. Choi JY, Jung SW, Kim HY, Kim Y, Kim DG, Oh EJ. Diagnostic value of AFPL3 and PIVKA-II in hepatocellular carcinoma according to total-AFP. World J Gastroenterol. 2013;19:339-46.

25. Wang WW, Ang SF, Kumar R, Heah C, Utama A, Tania NP, Li H, Tan SH, Poo D, Choo SP, Chow WC, Tan CK, Toh HC. Identification of serum monocyte chemoattractant protein-1 and prolactin as potential tumor markers in hepatocellular carcinoma. PLoS ONE. 2013:8:e68904.

26. Kalisman N, Schröder GF, Levitt M. The crystal structures of the eukaryotic chaperonin CCT reveal its functional partitioning. Structure. 2013;21:540-9.

27. Rüßmann F, Stemp MJ, Mönkemeyer L, Etchells SA, Bracher A, Hartl FU. Folding of large multidomain proteins by partial encapsulation in the chaperonin TRiC/CCT. Proc Nat Acad Sci USA. 2012;109:21208-15.

28. Lopez T, Dalton K, Frydman J. The mechanism and function of group II Chaperonins. J Mol Biol. 2015:427:2919-30.

29. Leitner A, Joachimiak LA, Bracher A, Mönkemeyer L, Walzthoeni T, Chen B, Pechmann S, Holmes S, Cong Y, Ma B, Ludtke S, Chiu W, Hartl FU, Aebersold R, Frydman J. The molecular architecture of the eukaryotic chaperonin TRiC/CCT. Structure. 2012;20:814-25.

30. Yokota S, Yamamoto Y, Shimizu K, et al. Increased expression of cytosolic chaperonin CCT in human hepatocellular and colonic carcinoma. Cell Stress Chaperones. 2001:6:345-50.

31. Wang S, Watanabe T, Noritake J, Fukata M, Yoshimura T, Itoh N, Harada T, Nakagawa M, Matsuura Y, Arimura N, Kaibuchi K. IQGAP3, a novel effector of Racl and Cdc42, regulates neurite outgrowth. J Cell Sci. 2007:120:567-77.

32. Hawthorn L, Luce J, Stein L, Rothshild J. Integration of transcript expression, copy number and LOH analysis of infiltrating ductal carcinoma of the breast. BMC Cancer. 2010;10:460.

33. Koon N, Zaika A, Moskaluk CA, Frierson HF, Knuutila S, Powell SM, El-Rifai W. Clustering of molecular alterations in gastroesophageal carcinomas. Neoplasia. 2004;6:143-9.

34. Shi Y, Deng X, Zhan Q, Shen B, Jin X, Zhu Z, Chen H, Li H, Peng C. A prospective proteomic-based study for identifying potential biomarkers for the diagnosis of cholangiocarcinoma. J Gastrointest Surg. 2013;17:1584-91.

35. Yang $Y$, Zhao W, Xu Q-W, Wang XS, Zhang $Y$, Zhang J. IQGAP3 promotes EGFR-ERK signaling and the growth and metastasis of lung cancer cells. PLOS ONE. 2014;9:e97578.

\section{Submit your next manuscript to BioMed Central and we will help you at every step:}

- We accept pre-submission inquiries

- Our selector tool helps you to find the most relevant journal

- We provide round the clock customer support

- Convenient online submission

- Thorough peer review

- Inclusion in PubMed and all major indexing services

- Maximum visibility for your research

Submit your manuscript at www.biomedcentral.com/submit
O Biomed Central 